\title{
A IMANÊNCIA, APRESENTAÇÃO DE UM ROTEIRO DE ESTUDO SOBRE GILLES DELEUZE ${ }^{1}$
}

\author{
Jairo Dias CARVALHO²
}

- RESUMO: O texto pretende mostrar um tipo de abordagem e de entrada no texto deleuziano. A partir do problema do fato da não existência de consenso no mundo da vida sentiu-se a necessidade de começar a pensar e formular um conceito de formas de vida. Escolheu-se, para isto, a idéia de plano de imanência e o conceito de multiplicidade virtual de Deleuze. Apresentamos, então, uma espécie de roteiro desse percurso. É o conceito de formas de vida, articulado e pensado a partir de Deleuze, a resposta ao problema da pluralidade e da diferença.

- PALAVRAS CHAVE: Plano de Imanência; multiplicidade virtual; analogia de proporção; formas de vida; Deleuze.

Nos aproximamos da filosofia de Deleuze a partir do problema da não-existência, de fato, de consenso no mundo da vida. Haveria formas de vida incompatíveis e que se excluiriam mutuamente? $\mathrm{O}$ fato do não consenso não obrigava a pensar uma multiplicidade intrínseca à vida, em cada vida? Haveria uma forma de vida superior como critério da lei, do justo, do direito, das formas de sociabilidade? Como a filosofia de De-

1 O texto é uma apresentação e um roteiro do percurso que fizemos na tese de doutorado "Plano de Imanência e Formas de vida, um estudo a partir de Gilles Deleuze", defendida na UFMG em 2002; foi apresentado em partes no I Encontro de filosofia francesa contemporânea realizado na USP, em maio de 2003.

2 Professor adjunto do Departamento de Filosofia do DEFIL da Universidade Federal de UberlândiaMG. 
leuze apresentava um conceito de múltiplo chamado de multiplicidade virtual, aparecia, assim, a idéia que devia ser combatida, a eminência, porque implica excelência e superioridade e a idéia de transcendência. Nosso problema era criticar a ilusão da existência de uma forma superior de ser.

A importância de se pensar um conceito de multiplicidade de formas de vida justifica-se porque acreditamos que é a pluralidade de uma vida e das vidas que produzem o não consenso no mundo da vida. A necessidade da filosofia de Deleuze está em seu conceito de multiplicidade virtual, porque talvez seja o conceito de pluralidade mais elaborado e rico da tradição. Elegemos como operador de conexões para entrar no texto deleuziano, o debate acerca do uso da analogia de proporção em alguns momentos da história da filosofia. Uso, este, que acarretava a idéia de eminência cuja figura central era a transcendência.

Organizamos a leitura de Deleuze em torno do problema da crítica à idéia de eminência. Não há como pensar a pluralidade radical de uma vida se aceitarmos as noções de superioridade e excelência que a idéia de eminência implica. Para pensar uma vida como multiplicidade é preciso pensar um mundo sem transcendência. Para pensar a vida como multiplicidade é preciso pensar o mundo sem a idéia de eminência. É que a transcendência é uma figura da eminência cuja gênese é o uso da analogia de proporção, que instaura um termo tomado como tipo para a atribuição de sentido e do valor aos outros termos em relação. Os termos em relação somente ganham valor e sentido a partir da participação proporcional ao termo tomado como tipo. Assim, na analogia de proporção há sempre um termo que possui mais valor e sentido que outros. Julgam-se os outros termos em relação a partir desse termo típico. A idéia de eminência reduz a multiplicidade à unidade. A idéia de transcendência é a constituição de um termo ou realidade radicalmente separada que possui por isso um sentido superior àquela realidade da qual é separada. Para se pensar em termos de multiplicidade não podemos pensar em termos de separação radical do sentido. O sentido é imanente ao múltiplo. Pensar em termos de multiplicidade é pensar que é na articulação intrínseca do múltiplo que o sentido se produz.

Deleuze tenta pensar a multiplicidade em si e por si. É na relação da multiplicidade com ela mesma, na relação dos "termos" de uma multiplicidade que há a produção do sentido e do valor. Como não pensar a vida a partir da idéia de eminência? Pensando-a como uma multiplicidade em si. Lemos Deleuze lendo a história da filosofia no sentido de pensar a vida sem a idéia de eminência e pensando-a como uma multi- 
plicidade em si. A gênese do problema da existência de uma forma superior de vida está no uso da analogia de proporção e a idéia de eminência que implica várias figuras, como por exemplo, a figura da transcendência. Este operador nos levou a Aristóteles, Plotino, Bruno, Scoto, Espinosa, Bergson e Nietzsche. Mostraremos a seguir uma parte desse percurso. ${ }^{3}$

\section{As filosofias da pluralidade dos sentidos de ser:}

1. As filosofias que pensam o sentido de ser referindo-o a um termo tomado como unidade de significação, ou seja, trata-se da remissão da unidade a um termo interno ao múltiplo. Esse campo trabalha a multiplicidade a partir da sua unidade interna. Sua formulação típica aparece em Aristóteles.

Aristóteles formula o problema dos muitos sentidos do ser e do uso da analogia de proporção. Esse campo orienta-se a partir de uma crítica às filosofias que pensam o ser como um gênero, como um coletivo. O ser é o que distribui o sentido. Chamamos a referência de significação dos termos de uma multiplicidade a um termo desta multiplicidade por analogia de proporção, mas melhor seria chamar de analogia de desproporção. Preferimos esta terminologia à "unidade focal de significação" (que indicaria melhor o que está em jogo neste campo) porque o próprio Deleuze usa "analogia de proporção". A analogia de proporção significa dizer que a relação de um termo com outro tomado como tipo não é a mesma relação de outro termo com este tomado como tipo. A manutenção do termo "analogia" se deve ao fato de que sem a relação qualquer que seja de um termo ou dos termos com este tomado como tipo não há significação. Em Aristóteles temos a constituição da filosofia dos muitos sentidos do ser e da analogia de proporção. Acreditamos que a exigência aristotélica de uma unidade focal de significação leva ao problema do incondicionado.

Em Aristóteles, o que nos interessou foi a sua formulação de que o ser se diz em vários sentidos, formulação que implica o uso da analogia

3 Como queríamos pensar o problema da multiplicidade de uma vida, e como, atentos a várias passagens da filosofia deleuziana que afirma ser sua filosofia uma teoria das multiplicidades, foi problema da articulação do múltiplo por si que orientou a escolha dos autores trabalhados em nosso estudo. 
de proporção. O ser se diz em muitos sentidos porque ancorado em uma analogia de proporção que referencia os muitos sentidos em um sentido tomado como tipo, a substância. A analogia de proporção concebe uma semelhança de A com B pela relação diferente que mantêm com X. É a relação com $X$ que permite falar em semelhança. Uma distribuição do sentido a partir de um referente-típico acarreta a idéia de eminência. A eminência pode ser concebida como a atribuição de superioridade de um termo em relação aos outros termos. A analogia de proporção ou unidade focal de significação elege um termo tomado como padrão de significação aos termos em relação. Este termo pode ser interior ao múltiplo, como é o caso da substância em Aristóteles. O uso da analogia de proporção é necessário a partir da exigência de não se pensar o ser como gênero. Estudamos Aristóteles porque sua filosofia é a gênese conceitual do uso da analogia de proporção. É em torno do uso, da crítica e da superação dessa analogia que aparece o pensamento da imanência em Deleuze. Lemos Aristóteles a partir da formulação em Deleuze de que o ser em Aristóteles possui um sentido distributivo e hierárquico e não coletivo, e da formulação de Muralt ${ }^{4}$ de que a analogia de proporção é uma das estruturas do pensamento. Concordamos em parte com Muralt. Para nós, o pensamento da univocidade do ser é uma tentativa de escapar do uso da analogia de proporção e mesmo de fundá-la. Não discutimos a leitura de Deleuze de Aristóteles, partimos de uma intuição sua e da leitura de Muralt para formular a gênese da idéia de eminência que é a atribuição proporcional de sentido a partir de um termo tomado como tipo.

2. As filosofias que pensam a unidade a partir de um termo externo ao múltiplo, esse campo pensa a multiplicidade a partir da unidade externa a esta multiplicidade. A unidade externa é focada num termo chamado de produtor ou modelo e cuja formulação aparece na filosofia de Plotino.

Plotino nos fornece uma imagem acabada da eminência, e mesmo na sua filosofia vemos funcionar a atribuição de sentido de modo desproporcional. Há uma filosofia dos muitos sentidos do ser em Plotino. A série das hipóstases implica uma hierarquia dos sentidos do ser. Em Plotino o que nos interessou é que sua filosofia, de certo modo, concebe a "unida-

4 MURALT, A de. Néoplatonisme et aristotélisme dans la métaphysique médiévale. Paris: Vrin, 1995. 
de focal de significação" como compreensão do Um além do inteligível. Plotino parte do problema platônico da imitação, mas a sua concepção da transcendência do Um é um movimento extremo da lógica da analogia de proporção de Aristóteles. Toda e qualquer eminência implica o uso da analogia de proporção, ou seja, a constituição de um termo que porta o sentido mais do que outros. Em Aristóteles esse termo é interno ao múltiplo, em Plotino é externo. Plotino ultrapassa o problema platônico da participação por imitação e coloca o problema em termos de produção do múltiplo, mesmo que esta produção seja externa ao múltiplo.

Segundo Deleuze, a tradição neoplatônica teria como tarefa reverter o problema platônico da participação. Esta tradição busca um princípio que tornaria possível a participação do ponto de vista do participado ele mesmo. Os neoplatônicos não partem dos caracteres do participante (múltiplo, sensível) para se perguntarem sob qual violência a participação torna-se possível. Eles tentam descobrir o princípio e o movimento interno que funda a participação no participado como tal, do lado do participado como tal. Não é o participado que passa no participante, o participado permanece em si, ele é participado pelo que ele produz, ele produz pelo que ele doa. Mas ele não sai de si para doar e produzir. Plotino, conforme Deleuze, pretende subordinar a imitação a uma produção, a uma gênese e substituir a idéia de uma violência por aquela de um dom. O participado não se divide e não é imitado de fora, nem constrangido por intermediários que fariam uma violência à sua natureza. A participação aqui não é imitativa, mas emanativa. Emanação significa, por sua vez, causa e dom, causalidade por doação, mas também doação produtora. A verdadeira atividade é aquela do participado, o participante não é senão um efeito, e recebe o que a causa lhe dá. A causa emanativa é a causa que doa. Quando buscamos o princípio de participação do lado do participado, devemos necessariamente encontrá-lo além dele.

O problema da filosofia de Plotino seria encontrar uma participação própria ao múltiplo que não significasse uma exterioridade como a teoria da imitação de Platão implicava. Quando pensa a participação em termos de produção, de emanação, ele descobre um princípio interno ao múltiplo. O Um é um princípio interno ao múltiplo porque o produz, mas é externo no sentido de que ele não é o que produz. O Um não é o todo, mas age internamente ao todo, produz internamente ao todo. Julga Plotino escapar de uma redução da multiplicidade à unidade pela exterioridade, que implicava a participação imitativa. No fundo, o problema todo é o da exterioridade da unidade do múltiplo. Julga Plotino que pensar a produção do múltiplo e não mais a imitação resolveria o problema 
da exterioridade, que seria mal fundada em Platão. Mas Plotino reintroduz uma exterioridade e a maior de todas: a supereminência do Um. Mas com a categoria de produção, o Um mesmo exterior ao que produz, age internamente no que produz. Plotino é uma figura complexa onde a imanência e a transcendência do Um estão em tensão.

Com Plotino temos, talvez, a maior figura da eminência, a transcendência do Um. Com Plotino aparecem os primeiros problemas de se pensar algo transcendente e ao mesmo tempo produtor, a complexidade da aceitação da existência de uma causalidade ora imanente ora transitiva, e a questão da exterioridade radical que porta o sentido do ser e do inteligível. O tipo em Plotino é além do ser e ao mesmo tempo constitui uma realidade. Com Plotino o tipo é uma realidade. Se com Aristóteles o tipo é interior ao múltiplo como tal, se bem que em certo sentido, a substância é pensada como pura forma, com Plotino o tipo é além do múltiplo. Não só reúne o sentido do múltiplo e também do ser, mas o produz, é condição de gênese do múltiplo. Plotino é a figura radical da eminência. É o horizonte de contraposição para se pensar o múltiplo em si.

Organizamos nossa leitura de Plotino a partir de Muralt, que mostra como Plotino radicaliza o uso da analogia de proporção. ${ }^{5}$ Ao lado disso, enriquecemos essa leitura a partir da centralidade da categoria de produção em Plotino. Não trabalhamos a leitura deleuziana de Plotino, que privilegia a noção de contemplação, mas tentamos mostrar que a filosofia de Deleuze quando ataca a eminência deveria atacar sua figura maior, o Um plotiniano. Tanto Plotino como Aristóteles ${ }^{6}$ configuram um campo de pensamento ao qual vão se contrapor Bruno, Espinosa, Bergson e Deleuze, os dois primeiros pelas teses da univocidade e imanência e os dois últimos pelas teses da imanência e lógica das multiplicidades.

\section{As filosofias da univocidade dos sentidos de ser}

\section{Duns Scoto}

A primeira filosofia da univocidade dos sentidos de ser é a de Duns Scoto. Sua filosofia apresenta a questão da inconsistência do uso da analogia de proporção que acarreta a eminência. Sejam dois termos em

5 Muralt, op.cit., p. 43.

6 Mesmo se as filosofias de Aristóteles e Plotino são diferentes, o primeiro, uma filosofia do ser, o segundo, uma filosofia do Um, ambos possuem uma afinidade secreta: pensam o múltiplo a partir de uma unidade originária, seja esta interior ao múltiplo (Aristóteles), seja exterior (Plotino). 
relação e em comparação, na analogia de proporção um dos termos será tomado como tipo ou critério para a atribuição do sentido do outro termo em relação. Scoto diz que uma relação de proporção, ou se quisermos desproporcional, exige um termo médio que seja comum aos dois em relação. É aí que concebe o conceito de ser como unívoco em suas determinações mais gerais, e é esse conceito neutro que serviria como termo médio ao uso da analogia de proporção. Sua crítica é radical. Com Scoto temos a univocidade do ser, o que significa que em suas determinações mais gerais o ser é dito de todo ente, o que acarreta a não- existência de uma forma ontologicamente superior de ser em suas determinações mais gerais. Há distinção entre os seres, mas esta não é ontológica. É este componente que nos interessa em Scoto. Há diferenças entre os seres, mas esta diferença não acarreta superioridade, pelo menos nas determinações mais gerais.

Nossa leitura de Scoto é totalmente deleuziana, mas enriquecida com a leitura atenta de Scoto na qual desdobramos e explicitamos várias das intuições de Deleuze. Um comentador nos foi também muito útil no nosso estudo sobre Duns Scoto, Olivier Boulnois, que traduziu a obra de Scoto para o francês. O interessante de sua leitura de Scoto é relacioná-lo ao debate acerca da sentido da metafísica de Aristóteles: ontologia ou teologia. Questão que nos ajudou e muito a compreender Deleuze e relacionar Scoto, Bruno e Aristóteles, e montar o debate histórico acerca do problema da alternativa entre analogia e univocidade. ${ }^{7}$

Scoto, ao atacar o problema da eminência, dizendo que para que haja uma comparação analógica que permita a atribuição de superioridade de um termo em relação a outro é necessário um termo médio, ataca tanto a posição aristotélica quanto a posição neoplatônica. Se a resposta plotiniana e a exigência aristotélica são típicas, a crítica scotista também é, e neste sentido ela é fundante de uma tradição da qual beberá a filosofia de Deleuze. A univocidade é tanto um ataque a uma posição neoplatônica quanto aristotélica e componente de um outro campo: a filosofia das multiplicidades de Deleuze.

\section{Giordano Bruno}

Giordano Bruno vai aceitar a univocidade do ser e dizer que ela é real e não conceitual como em Scoto. É como se Bruno dissesse a Scoto

7 Questão que aparece na introdução de Olivier Boulnois na sua tradução de Scoto no livro SCOT, Jean Duns. Sur la connaissance de Dieu et l'univocité de l'étant. Paris: PUF, 1988. 
que se em Plotino a eminência é uma realidade, a univocidade também deveria ser, por isso a univocidade do ser como real no conceito de natureza naturante.

Com Bruno temos uma idéia de univocidade relacionada à totalidade e correspondendo a uma realidade e não a um conceito como em Scoto. Com Bruno temos uma interpretação naturalista de Parmênides. Tudo o que é dito ser ou é natureza naturante ou natureza naturada. Mas a natureza naturante é a realidade infinita do universo. Como Bruno temos a noção de que não há uma exterioridade radical à natureza. Bruno introduz o absoluto na natureza. A natureza é o absoluto de si. Bruno acrescenta à tese da univocidade do ser, que significa a idéia de uma não eminência dos entes ao pensamento, a idéia de que a transcendência é um horizonte de nosso modo de conhecer as coisas. É o nosso modo de pensar que acarreta a idéia de transcendência.

A univocidade real de Bruno que é uma vantagem em relação à posição scotista, é também uma crítica a Aristóteles, mas a partir do neoplatonismo. Bruno aceitaria a formulação plotiniana da produção do múltiplo pelo Um, mas o Um não é exterior à totalidade. O Um é a natureza naturante. Com Bruno a univocidade é real e a produção do múltiplo é interna ao múltiplo. Com Bruno a univocidade scotista é relacionada à imanência. Bruno significa uma passagem da univocidade à imanência.

Lemos Bruno a partir da formulação de Deleuze de que em Bruno o conceito de complicação recebe uma determinação completa. E é a noção de complicação em Bruno que permite falar de univocidade e não existência de um fora radical à natureza. A natureza naturante é a complicação de todas as coisas e a natureza naturada a sua explicação. Deleuze aproveita esta tese para montar sua leitura de Espinosa. Lemos Bruno, também, a partir de Tristan Dagron. ${ }^{8}$ Sua tese de que Bruno lê Parmênides imanentizando-o, e de que a transcendência é uma ilusão necessária de nosso modo de pensar foi muito útil na nossa compreensão de Bruno.

Deleuze não possui um trabalho de fôlego sobre Bruno, mas queremos arriscar dizendo que a filosofia de Bruno poderia ser mais útil a Deleuze se não elegesse Espinosa, sensível que é à exigência cartesiana da existência do atributo principal para qualificar uma substância. Formulemos melhor esta questão que para nós é decisiva.

8 DAGRON, Tristan. Unité de l'être et dialectique: L'idée de philosophie naturelle chez Giordano Bruno. Paris: PUF, 1998. 
Para conceber a relação plano de imanência/multiplicidade virtual que para nós é a formulação mais rica da filosofia deleuziana, e que a torna consistente e apta a entrar nos vários debates filosóficos contemporâneos, Deleuze vai operar uma modificação em Espinosa a partir de Bergson e Nietzsche. Na maioria das vezes ele opera com a tríade substância/atributo/modo. Mas ao fim utiliza a relação substância/atributo como um componente essencial para conceber a relação plano de imanência/multiplicidade virtual. Deleuze, quando estuda Espinosa, é a noção de expressão na definição seis do livro Um da Ética que ganha valor estratégico, mas na sua apropriação de Espinosa para a formulação de sua filosofia própria é a definição quatro que é mais importante. O recurso a Espinosa poderia ser menos problemático se Deleuze operasse com a distinção natureza naturante e natureza naturada de feita por Giordano Bruno. Distinção esta, que é diferente da de Espinosa, pois não há a noção de atributo, mas apenas substância e modos. Apenas a relação substância/atributo em Espinosa interessaria a Deleuze. Deleuze no fundo não é espinosista. Ele acompanha Espinosa até certo ponto. Deleuze não aceitará a relação substância/modo em Espinosa. Não aceitará porque, mesmo não havendo uma diferença eminente entre substância e modo, isso garantido pela mediação do atributo, que explica e constitui a substância e está implicado nos modos, Deleuze não aceita a idéia à distinção do "em si" e "em outro". É o "em si" da substância que é problemático a Deleuze. Uma filosofia das multiplicidades não poderia aceitar a idéia, por exemplo, de uma multiplicidade em si, pois são sempre em relação. Quando dissemos acima que pretendíamos pensar a vida como uma multiplicidade em si mesma, não queríamos dizer que existe uma multiplicidade em si, pois as multiplicidades são em relação, mas que queríamos pensar as multiplicidades não a partir da unidade tomada como posição primeira.

Com Bruno, Deleuze estaria mais à vontade porque o "em si" complicante é todo ente, se bem que existe ainda em Bruno uma disjunção, complicação e explicação, mesmo se o que é "explicado" é intrínseco ao que "complica", o que complica é o todo. É como se em Bruno tivéssemos apenas substância e modos. Mas a relação substância/modos (natureza naturante e natureza naturada) em Bruno é uma relação que interessa a Deleuze, porque há uma relação de interioridade radical entre os termos em relação, natureza naturante e natureza naturada sem o recurso de um termo médio, como em Spinosa através do atributo. É que Espinosa compreende Descartes na exigência de qualificação de uma substância por um atributo principal, mas modifica este problema 
transformando-o no problema de constituição da substância e da percepção dessa constituição pelo nosso intelecto, que nomeia o que constitui a essência da substância, de atributo. Essa relação de interioridade entre natureza naturante e natureza naturada é diferente da relação entre substância e modo em Espinosa, mas próxima da relação substância/ atributo spinozista. Contudo, por ser uma questão importante para nós, desenvolveremos esse ponto mais detidamente já que estamos afirmando um lugar de Bruno na "univocidade" deleuziana.

\section{A imanência em Bruno}

Bruno refere a série múltipla a uma unidade tomada não como um termo interior à série (Aristóteles), nem como um termo supereminente fora da série (Plotino), nem como uma unidade neutra conceitual (Scoto) mas como real: a totalidade da natureza. À exigência de unidade por Scoto, Bruno acrescenta que esta unidade não é interior nem exterior à multiplicidade, é produtora da multiplicidade. Mas não séries como as hipóstases plotinianas que derivam de um termo. A natureza é um meio como princípio das coisas naturais, onde todas as formas existem em estado complicado. A unidade em Bruno é a unidade de um mundo. Mas não há uma realidade extrínseca à natureza. A natureza identificada ao ser não caracteriza uma hipóstase ou uma substância distinta das coisas naturais. Bruno não aceita que esta hipóstase seja pensada como um ser inteligível separado das realidades naturais submetidas ao devir. As coisas naturais existem na natureza, que as produz em si mesma.

Para Bruno, o universo é um, infinito, imóvel. O universo é indefinível, não-limitável, infinito e, por conseqüência, imóvel. É imóvel como infinito, pois se se movesse para algum lugar haveria um fora dele mesmo para o qual se moveria. O universo é o todo. Assim, também ele não se engendra, no sentido de que não se produz como um todo, já que é todo o ser. Não se corrompe, porque não há nada em que pudesse se transformar, não se transforma como todo. Não pode diminuir-se nem crescer, o universo é o Um infinito. Não muda de disposição, porque nada de exterior produz nele qualquer afecção. O universo compreende tudo, todos os contrários em seu ser de uma maneira harmoniosa e unitária. Não podemos admitir um contrário ou alguma coisa de diferente dele que o possa alterar, porque nele tudo concorda. Não é matéria, porque não tem nem figura nem limite, isto no sentido de que ele é matéria não formada. Mas não podemos dizer que engloba a si próprio, que não é maior que si mesmo, e por isto não é compreendido nele mesmo. Sendo Um e idêntico, não existem seres distintos dele. Não tem partes, no 
sentido de que não é uma multiplicidade discreta. No infinito não há diferenças entre as coisas. Como ele compreende tudo, não comporta nem por si nem em si nenhuma mudança, como todo. O universo é em tudo, porque tudo é um. O universo é tudo e compreende em si todo o ser.

A mudança, então, não visa a um outro ser, mas um outro modo de ser. Esta é a diferença entre o universo e as coisas do universo, porque se o universo compreende todo o ser e todos os modos de ser, cada uma das coisas possui o ser, mas não todos os modos de ser. Cada coisa não pode possuir em ato todos os modos, as particularidades e todos os acidentes porque muitas formas são incompatíveis em um mesmo substrato. O universo compreende todo o ser totalmente, porque nada pode existir fora e além do ser infinito; cada uma das coisas do universo compreende todo o ser, mas não totalmente porque fora de cada uma delas existe uma infinidade de coisas. Tudo é um, mas não totalmente nem sob todos os modos em cada coisa. Cada coisa é una, mas não sob um modo único. No um se encontra a multiplicidade, o ser é um, mas multimodal, multiforme e multifigurado. Todas as coisas são no universo e o universo em todas as coisas.

No ser encontram-se todas as formas, todas as figuras e todos os membros, mas indistintos e por assim dizer aglomerados, exatamente como na semente, onde o braço não se distingue da mão, dos nervos, e onde a diferenciação não produz uma outra ou uma nova substância, mas atualiza certas qualidades, certas diferenças, certos acidentes e certas disposições relativos a essa substância. Assim, há uma só e mesma substância que se chama ser, o fundamento de todas as espécies e formas diversas. O um compreende todo o ser sob o modo da complicação, e sob o modo da explicação ele se encontra nas coisas naturais.

A univocidade em Bruno é real, ela é a unidade que é tudo, é aquela que não é explicada, que não se encontra na distribuição e na distinção numérica, mas que é a unidade que complica e que compreende tudo. Essa unidade é produtividade infinita, mas é ato que permanece em si. O ato interior do Um produz um efeito interior, e o que é engendrado é produzido dentro de si mesmo.

Bruno quer uma univocidade real. E é neste sentido que dialoga também com Plotino, com a natureza de produtor do Um. O Um é uma realidade, e se há univocidade ela deve ser também uma realidade e é, então, que Bruno concebe o conceito de complicatio - a natureza naturante é a complicação de todas as coisas e é este conceito a alternativa ao conceito de univocidade em Scoto, mas também a Aristóteles e a Plotino. O que nos interessa em sua filosofia é o conceito de complica- 
ção e a idéia de que não há um fora radical à natureza. O conceito de natureza como complicação de todas as coisas torna a univocidade real. Mas o fato da transcendência, que é um efeito do nosso modo de conhecer, nos deixa entrever a grande revolução que representa a filosofia de Espinosa.

A Deleuze interessaria em Bruno a relação natureza naturante/natureza naturada, porque esta relação lhe permitirá pensar a univocidade aplicando esta relação a todo "ente". Nossa hipótese é que, para pensar a relação plano de imanência/multiplicidade virtual, Deleuze vai se apropriar da relação substância/atributo de Espinosa e da relação natureza naturante e natureza naturada de Bruno.

\section{Espinosa}

Por isso em Espinosa estudamos a relação substância/atributo de forma privilegiada. Com Espinosa, a partir da noção de atributo, obtivemos a idéia de que não há forma superior de ser e de que não há exterioridade absoluta à natureza, e o grande avanço, a idéia de que os atributos são formas diferentes entre si, mas se reportam ontologicamente à substância. A substância difere em si, e o atributo é sua constituição. Há uma relação intrínseca, revelada pela noção de expressão, que trabalhamos exaustivamente, entre os constituintes expressivos e o que os engloba. A substância produz a si mesma distinguindo-se em constituintes expressivos. Nosso intelecto percebe essa constituição da substância e chama os constituintes de atributos. O expresso, a substância não existe fora da sua expressão, o atributo. É essa relação que Deleuze utiliza para pensar a relação plano de imanência/multiplicidade virtual. Portanto, é central na compreensão deleuziana de Espinosa a noção de expressão. Se Espinosa em certo sentido representa uma figura importante, em Deleuze é que a univocidade scotista torna-se absolutamente real com o conceito de substância. Mesmo se Espinosa não é a figura acabada da univocidade para Deleuze, Espinosa pensaria o conceito de ser (a substância) como qualificado e não neutro como em Scoto. É a formulação típica da filosofia de Bruno que permite a Deleuze compreender Espinosa. É o problema da complicatio que permite a Deleuze compreender a noção de expressão de Espinosa. E é um avanço em relação a Bruno, porque a transcendência não é efeito do modo de conhecimento, e sim não-existente. Espinosa é uma figura típica importante porque sua filosofia tanto é uma crítica ao problema aristotélico do uso da analogia de proporção quanto uma formulação, agora nos quadros da 
univocidade e imanência, do problema da produção do múltiplo plotiniana. Com Espinosa não há transcendência/eminência, mas uma determinada lógica do múltiplo.

\section{Conclusão}

Por isso acreditamos que Deleuze se apropria da noção de complicação de Giordano Bruno, da noção de expressão e da relação entre substância e atributo em Espinosa, de multiplicidade virtual em Bergson, da questão da repetição e diferença em Nietzsche e constitui um pensamento não a partir da tríade substância/atributo/modo de Espinosa, ou da díade natureza naturante/natureza naturada de Bruno, mas de um quadrado: caos/plano de imanência/ multiplicidade virtual/multiplicidade atual, ou, se quisermos, na terminologia de Diferença e Repetição, a complicação/perplicação/implicacão/ explicação, mas atribuindo esse quadrado a todo ente. Essa é a univocidade deleuziana.

Nosso roteiro de leitura de Deleuze aponta, então, para uma aplicação. Depois de estudar debate acerca da analogia e univocidade e de vermos a mudança de foco que a filosofia de Bergson fornece a Deleuze, questão que não apresentamos aqui, aplicamos a relação caos/plano de imanência/multiplicidade virtual/multiplicidade atual ao conceito de vida e a pensamos como multiplicidade intrínseca. O termo "formas de vida" se refere às multiplicidades virtuais implicadas em uma vida, e as "formas" seriam os atributos de cada vida, questão que pretendemos trabalhar em outro artigo.

Portanto, organizamos o texto deleuziano a partir do movimento da passagem do uso da analogia de proporção ou de atribuição a uma lógica das multiplicidades. Passagem, aqui, significa não uma superação, mas mudança de natureza, uma diferenciação no modo de pensar. Será uma lógica das multiplicidades a partir de Deleuze e Bergson a alternativa ao uso da analogia de proporção e que proporcionará essa passagem do modo de pensar. Não explicitamos a leitura de Deleuze da história da filosofia, mas a lemos a partir do nosso foco. Lemos Deleuze e sua leitura da história da filosofia a partir das questões em torno do uso da analogia de proporção e da alternativa a esse uso representado pela relação entre a idéia de plano de imanência e do conceito de multiplicidade virtual. É nesse debate que concebemos a vida como multiplicidade infinita e chamamos cada configuração sua de forma.

É a relação plano de imanência/multiplicidade virtual, resposta deleuziana ao problema do debate acerca do uso da analogia de propor- 
ção/univocidade, um componente essencial para se pensar a vida como multiplicidade de formas e de pretensões de sociabilidade, resposta mais consistente ao problema de fato do não consenso no mundo da vida. É a partir dessa hipótese que nos aproximamos de determinados autores, conceitos e filosofias, e principalmente de Deleuze.

CARVALHO, J. D. Immanence plan and forms of life - presenting a study guide about Gilles Deleuze. Trans/Form/Ação, (São Paulo), v.28(1), 2005, p.119-132.

- ABSTRACT: This text intends to show a kind of aprproach and introduction to Deleuze's work. Based on the problem of the non-existence of consensus in the world of life, we feel the need to start thinking and formulating the concept of virtual multiplicity. Then we present a kind of guide to do so. The solution to the problem of plurality and difference is the concept of forms of life formulated and thought in acordance with Deleuze.

- KEYWORDS: Plan of Immanence; virtual multiplicity; analogy of proportion; forms of life; Deleuze.

\section{Referências bibliográficas}

AUBENQUE, Pierre. Les origines de la doctrine de l'analogie du l'être. In. Les Études Philosophiques: Aristote et l'Aristotélisme, Janvier-Mars, Paris: PUF, 1978, p. 3-12.

BERGSON, H. L'Evolution Créatice. Paris: PUF, 1946.

Essai sur les données immédiates de la conscience. Sexta edição. Paris: Quadrige/ PUF, 1997.

BRUNO, G. De la cause, du principe et de l'un. Trad. Luc Hersant. Paris: Les Belles Lettres, 1996.

DAGRON, Tristan. Unité de l'être et dialectique: L'idée de philosophie naturelle chez Giordano Bruno. Paris: PUF, 1998.

DELEUZE, G. Différence et répetition. Paris: PUF, 1968. 1968.

Spinoza et le problème de l'expression. Paris: Éditions de Minuit,

Niezstche et la philosophie. Segunda edição. Paris: Quadrige/ PUF, 1998.

Le Bergsonisme. Segunda edição. Paris: Quadrige/ PUF. 1998.

MOURÉLOS, G. Bergson et les niveux de réalité. Paris: PUF, 1964.

MURALT, A. de. Néoplatonisme et aristotélisme dans la métaphysique médiévale. Paris: Vrin, 1995.

SCOTO, J. D. Sur la connaissance de Dieu et l'univocité de l'état. Trad. Olivier Boulnois. Paris: PUF, 1988. 